\title{
Simple and complicated hypertrophic pyloric stenosis in the adult
}

\author{
W. MILO KEYNES \\ From the Nuffield Department of Surgery, The Radcliffe Infirmary, Oxford
}

EDITORIAL SYNOPSIS From this study of hypertrophic pyloric stenosis in adults it is concluded that the cause is essentially genetic and the condition is due to the persistence or late development of 'congenital hypertrophic pyloric stenosis'. Focal hypertrophy involving only a portion of the pylorus may occur. A detailed study of the clinical, pathological, and radiological features is presented.

Simple, primary, or idiopathic hypertrophy of the pyloric muscle in the adult resembles the congenital pyloric hypertrophy of infants, and no associated lesion, such as a peptic ulcer, is apparent. The hypertrophy, which narrows and elongates the pyloric canal, is limited to the muscle of the pyloric sphincter and, most commonly, mainly involves the circular muscle; sometimes it is focal. The condition is benign and may be treated by simple splitting of the muscle as in the congenital variety. Its recognition may, however, be difficult and it may be mistaken for a pyloric carcinoma radiologically, or at operation, so that an unnecessarily wide resection is performed.

Similar muscle hypertrophy limited to the pyloric canal has been more commonly observed in association with both benign and malignant peptic ulceration not necessarily in the pyloric region (Kirklin and Harris, 1933; Desmond and Swynnerton, 1957), and it has also been noted with gastric polyposis (Prinz, 1939) and with hypertrophy of the mucosal rugae (Zacho, 1948). Such pyloric muscle hypertrophy has usually been called 'secondary', though a better term is 'complicated', since secondary implies that the associated lesion is the known cause of the hypertrophy.

A recent review of simple hypertrophic pyloric stenosis in the adult (Christiansen and Grantham, 1962) commented on its rarity. With the 64 records collected from, or added to, the literature by North and Johnson (1950), these authors reviewed a further 56 reported since 1950 , as well as adding two new case histories. Three further examples recorded by McNaught (1957), five by Feraru, Rosemond, Irons, and Zaino (1961), one by Woo-Ming, (1961), and one by McLaughlin and Madding (1962) bring the total so far described to 132 .
A personal experience of four adult patients with pyloric muscle hypertrophy in a year led to a search through just over 200 records at St. Bartholomew's Hospital listed from 1950 to 1959 under the heading 'pyloric stenosis', and seven more were traced. A further record was obtained from the Royal Masonic Hospital. In this paper we describe the clinical, radiological, and pathological findings in these 12 patients, six of whom had peptic ulcers (three duodenal, two gastric, and one pyloric). The six with simple hypertrophic pyloric stenosis can be added to the 132 previously recorded. Although uncommon we do not believe that adult pyloric hypertrophy is as rare as the literature seems to suggest.

\section{HISTORY}

The first description of simple hypertrophic pyloric stenosis in the adult was in 1835, in Paris, when Jean Cruveilhier reported the death of a woman of 71 years from persistent vomiting, with the finding of pyloric muscle hypertrophy at necropsy. In 1885, Maier described 31 examples from post-mortem studies in 26 men and five women whose ages ranged from 12 to 80 years. He thought that the condition had been present in mild form since infancy, but from his description it is improbable that all his patients had the disease.

Robson and Moynihan (1901) reported the first surgical cure, in a man of 24 years, following gastrojejunostomy for simple pyloric muscle hypertrophy and since then reports on this condition (without other significant lesions in the stomach or duodenum) have accumulated. Graham (1920) and Bastianelli (1925) described cure by a Ramstedt procedure in five patients, and in 1930, Morton reported two cases 
treated by pyloroplasty. Barling (1913) was the first to report on the histology, and Kirklin and Harris (1933) wrote the first important paper on the radiological appearances. At the Mayo Clinic from 1927 to 1931,81 cases were found in 60,000 barium meal examinations, but the majority of these had other intra-abdominal disease (duodenal ulcer 17; gastric ulcer 13; gall-bladder disease 12; and 'chronic appendicitis' 5). Carcinoma of the pylorus is an important differential diagnosis.

\section{ANATOMY OF THE PYLORUS}

The arrangement of the muscle of the pylorus is not simple, since the pyloric sphincter has the power of active dilatation as well as of active contraction (Cunningham, 1906). Horton (1928) showed that about half of the longitudinal fibres dip into the underlying circular muscle to form the dilator muscle of the pylorus. Some of the longitudinal fibres are continuous with those of the duodenum, but in most there is a complete break between the circular muscle of the pylorus and that of the duodenum. Connective tissue septa divide the circular muscle into units.

Torgersen (1942) confirmed that the majority of the longitudinal fibres dip into the underlying connective tissue in the pyloric circular muscle. He also showed, in mammals, that the circular muscle is arranged in sphincteric loops or thickenings. The pyloric sphincter proper, at the pyloric ring, is composed of two parts; one of these is a thin duodenal component and the other a thicker gastric component which he called 'the right canalis loop'. Another thickening, or intermediate sphincter, encircles the proximal end of the pyloric canal obliquely, and this he named 'the left canalis loop'. The two loops converge at the lesser curvature to form a muscle torus or knot. The torus and right loop are better developed than the left loop in man and constitute the muscle band normally felt at the pylorus.

In man, on average, the circular muscle of the pylorus is $3 \mathrm{~mm}$. thick and the longitudinal muscle $1.25 \mathrm{~mm}$. thick (Crymble and Walmsley, 1933). Horwitz, Alvarez, and Ascanio (1929) gave a higher figure of $5.8 \mathrm{~mm}$. for the combined thickness of these muscles, with a range of 3.8 to $8.5 \mathrm{~mm}$. in 47 fixed specimens in which the sphincter has been previously sectioned. Knight (1961) measured the dimensions of the pyloric muscle in 10 fresh postmortem stomachs and the thickness ranged from 4 to $7 \mathrm{~mm}$. with an average of $5.1 \mathrm{~mm}$. Craver (1957) also studied 10 fresh specimens and found that the average thickness of the circular muscle was $4.4 \mathrm{~mm}$., with a range of from 3 to $8 \mathrm{~mm}$. The normal pyloric canal on radiology is about $1 \mathrm{~cm}$. in length (Kirklin and Harris, 1933; Edwards, 1961). There is obviously variation in the normal, but these measurements give a basis for comparison when considering hypertrophy of the pyloric muscle.

\section{INCIDENCE}

The incidence of adult pyloric hypertrophy is not known, since only the patients with more severe symptoms will come to operation and be diagnosed. Over a 24-year period, 1932 to 1956, at the New York Hospital-Cornell Medical Centre, Craver (1957) collected 11 cases of simple, and 155 of complicated, hypertrophy. Desmond and Swynnerton (1957), in London, encountered 25 patients with pyloric muscle hypertrophy (seven simple and 18 complicated) over a 10-year period at St. James's Hospital. In the majority of reported cases where measurements were made, the thickness of the pyloric muscle was from 1 to $1.5 \mathrm{~cm}$. (and even as thick as $3 \mathrm{~cm}$. in some).

The ratio of male to female in 138 patients with simple pyloric hypertrophy was 2 to 1 . The ages of our six patients varied from 57 to 74 years, with an average of 63. The extremes of age in the collected series were 14 and 85 years, with an average of 49 years, and most of the patients were between 50 and 70 years old. Our six patients with complicated hypertrophy showed the same sex ratio of two males to one female, and their average age was 55 years.

\section{PATHOLOGY}

A main difference between the adult condition and the pyloric hypertrophy of infants is that, whilst in infants the hypertrophy involves the whole circumference of the pylorus (Fig. 1), in the adult it may only involve a limited segment (Bachmann, 1952). In the infant the hypertrophy is simple, since there is no other gastrointestinal pathology, but in the adult there may be associated peptic ulceration, gastric polyposis, or hypertrophic gastritis (Fig. 2). Skoryna, Dolan, and Gley (1959) classified adult pyloric hypertrophy and included the diffuse form with proximal (gastric) lesion under the heading of 'primary', whilst defining the 'secondary' condition as that associated with distal obstructive lesions. We prefer to classify the disease as either simple or complicated (see aetiology section). In the simple condition there is no apparent associated gastrointestinal disease and the hypertrophy may be diffuse or focal. The complicated condition, as reported, has usually been diffuse hypertrophy.

Focal hypertrophy involves only a part of the pyloric circular muscle and usually corresponds anatomically to the muscle torus on the lesser 


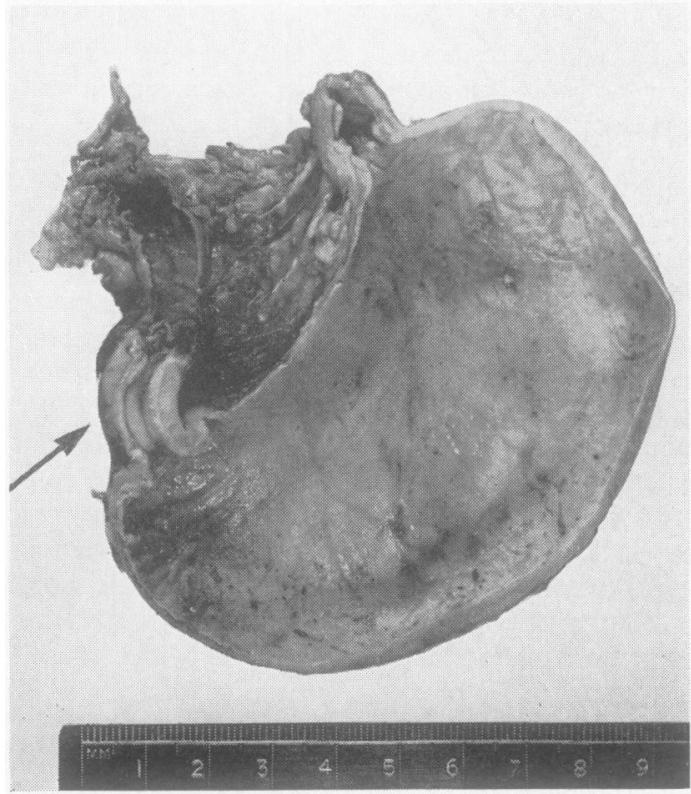

FIG. 1.

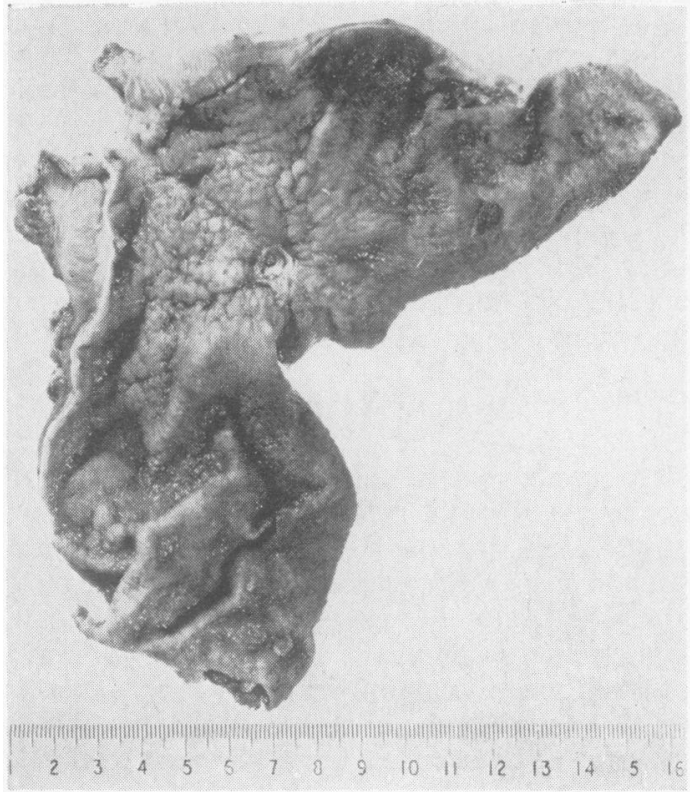

FIG. 2.

FIG. 1. The opened stomach and pyloric canal from an infant who died with congenital pyloric stenosis. The arrow points to the hypertrophied pyloric muscle.

FIG. 2. The opened specimen from an adult (patient A.K.) with complicated pyloric hypertrophy treated by partial gastrectomy. The hypertrophied muscle $1 \mathrm{~cm}$. thick is seen at the pylorus with a proximal gastric ulcer.

curvature of the pylorus (Keet, 1956; Skoryna et al., 1959; Knight, 1961); it may, however, occur anywhere in the pylorus (Knight, 1961). It it not known whether the focal form is a separate entity from the diffuse form, and it may be confused with a gastric polyp or a local pyloric carcinoma or leiomyoma at operation. None of our patients had focal hypertrophy, but Bachmann (1952) recorded finding 12 examples in $600(2 \%)$ necropsies and considered that its frequency was higher than the diffuse hypertrophy.

The gross appearance of the pylorus in diffuse adult pyloric hypertrophy, both in the simple and in the complicated, is similar to that found in infancy. There is a smooth, firm or rubbery, tumour occupying the region of the pylorus and ending abruptly at the duodenum, with lengthening and narrowing of the pyloric canal. The thickest part is usually at the distal end of the pyloric canal, and proximally it gradually decreases in size. On section the obvious change is hypertrophy of the circular muscle layer (Fig. 3), but occasionally the longitudinal muscle may also show moderate hypertrophy (North and Johnson, 1950).

Histological examination shows hypertrophy of the circular muscle fibres (Fig. 4) and, sometimes, of the longitudinal fibres (North and Johnson, 1950). Crymble and Walmsley (1933) noted a thinning of the longitudinal muscle in their case. In several of our cases there was an increase in the amount of fibrous connective tissues between the bundles of hypertrophied muscle, and in one some of this muscle showed degenerative changes. One biopsy specimen from a patient with the simple disease showed obliterative endarteritis (without any inflammatory changes), and this was also noted in one patient with a duodenal ulcer.

We noted no abnormality in the ganglion cells of Auerbach's myenteric plexus, lying between the circular and longitudinal muscle layers (Fig. 5), but in several specimens there was apparently an increased number of nerve fibres. Degenerative changes of the ganglion cells have been reported by other authors (Belding and Kernohan, 1953; Raia, Curti, Cardoso de Almeida, and Fry, 1956).

In adult pyloric hypertrophy there are generally no inflammatory changes or oedema (Craver, 1957), but such reaction has been described in the mucosa and in the submucosa (North and Johnson, 1950), when especially round cell infiltration may be present (McNamee, 1933). One of our specimens of simple hypertrophy showed chronic inflammatory cells in 


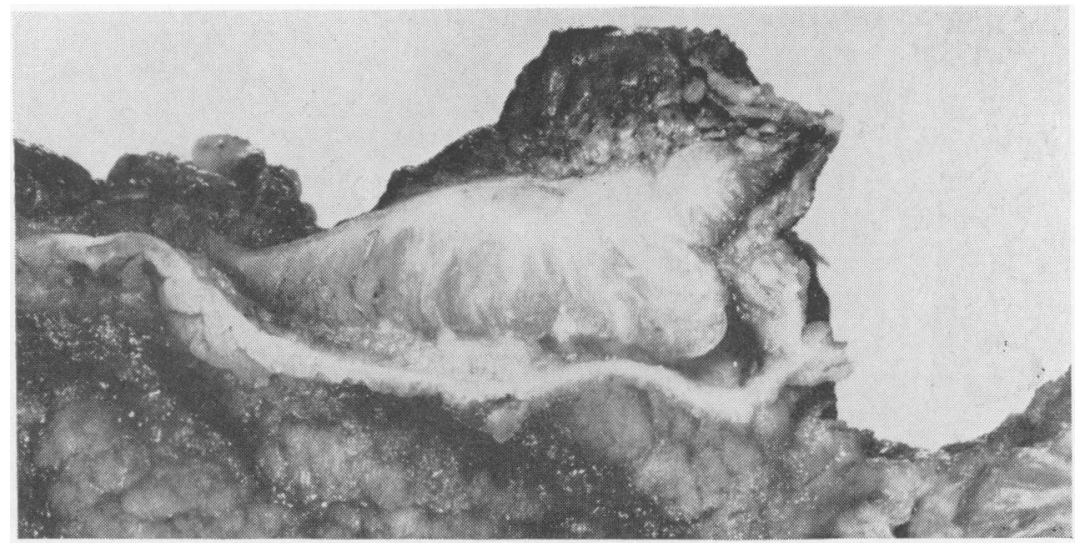

FIG. 3. Macroscopic view of adult pyloric muscle hypertrophy (patient A.K.) on section. The hypertrophy of the circulatory muscle bundles is seen.

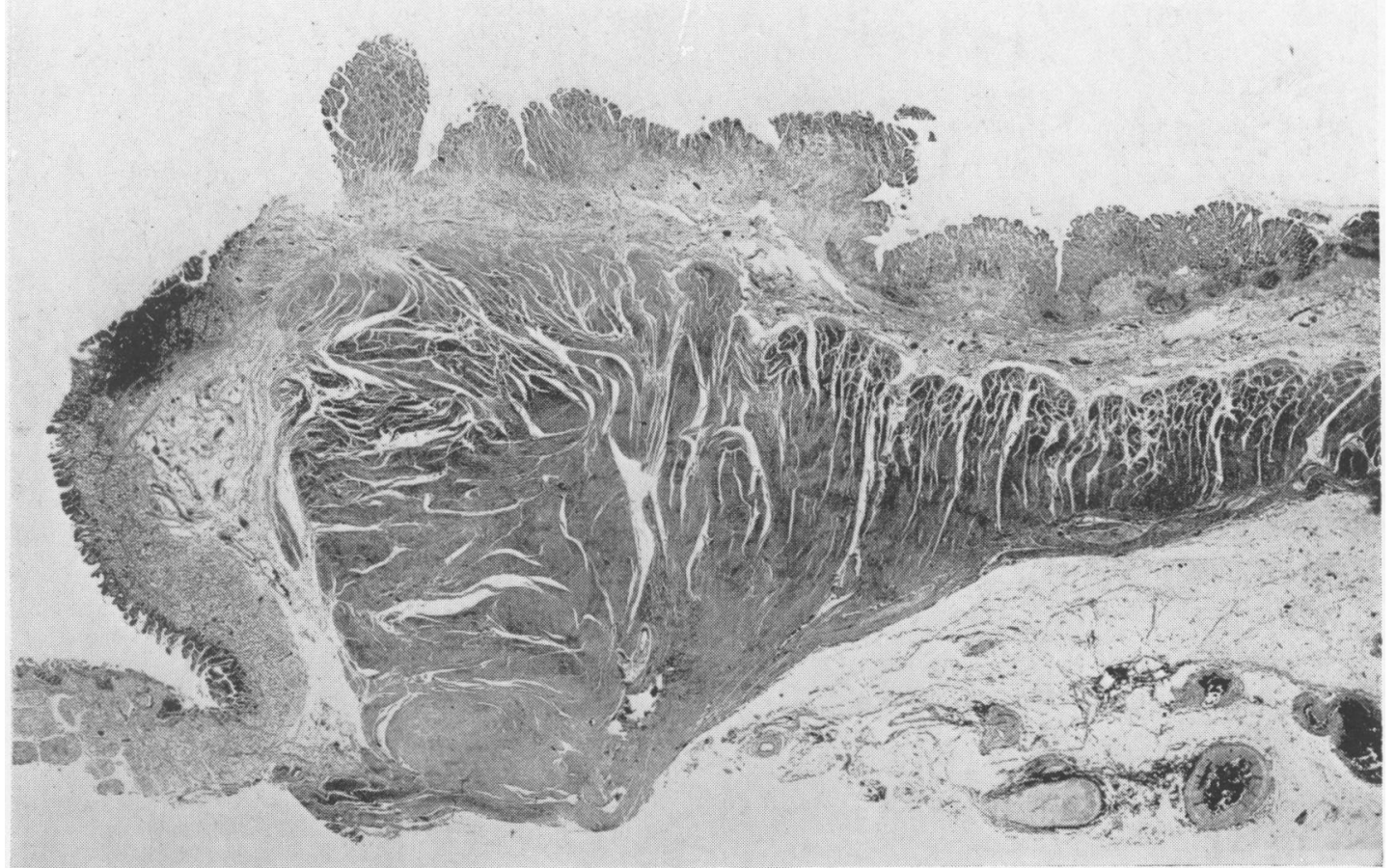

FIG. 4. Photomicrograph of longitudinal section of adult pyloric hypertrophy (patient A.K.) showing hypertrophied bundles of the circular muscle with strands of fibrous connective tissue in between the bundles. Haematoxylin and eosin $\times 7$.

the submucosa, and in another there was round cell infiltration in the muscle layers. Three of the specimens of complicated hypertrophy (out of five where histology was available) showed inflammatory changes and in all these the peptic ulcer was near or in the pyloric canal. North and Johnson (1950) considered that the intensity of inflammatory reaction in the simple disease depended on the duration and degree of pyloric obstruction, and oedema and inflammatory cells may also be present in the mucosa and submucosa in the infantile form (Wollstein, 1922; Bodian, 1963). Skoryna et al. (1959) thought that simple hypertrophy should only be diagnosed when there is no fibrous tissue formation to indicate a previous inflammatory process. Such fibrosis (with local endarteritis obliterans as well) was present in one of our specimens of complicated hypertrophy from a patient with a duodenal 


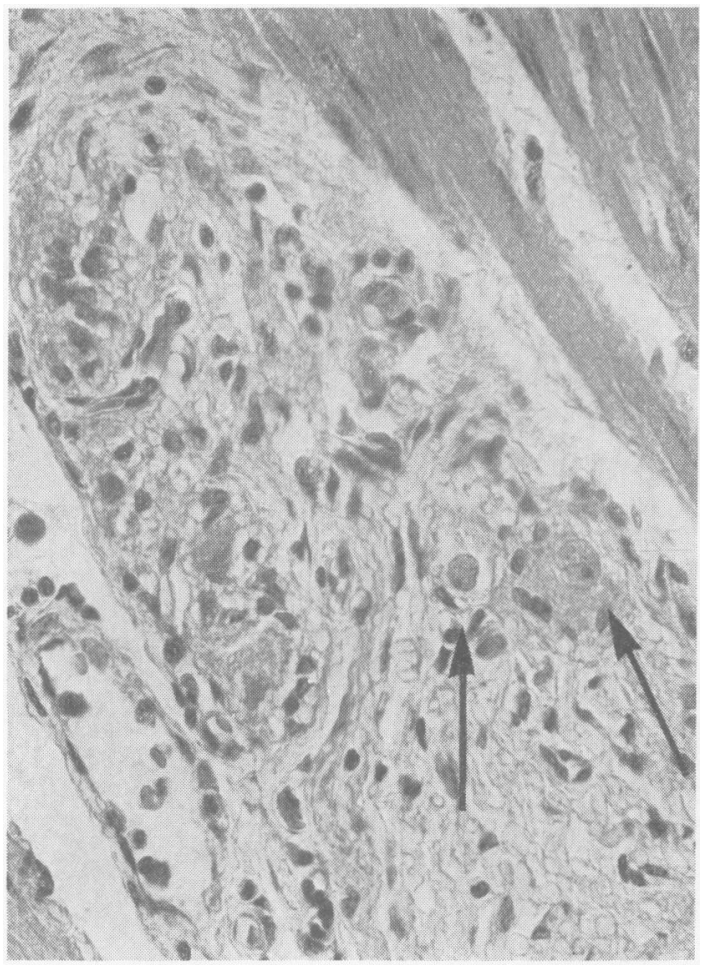

FIG. 5. Adult pyloric hypertrophy. The arrows point to normal ganglion cells of Auerbach's plexus. Haematoxylin and eosin $\times 450$.

ulcer, and also in another from a patient with a healed pyloric ulcer.

\section{RADIOLOGY}

The radiological changes in my series are shown in Figures 6-9.

The radiological changes in simple hypertrophic pyloric stenosis in adults were first described in this country by Twining (1933) in three patients. He separated pyloric narrowing due to hypertrophied muscle from other causes of narrowing of the pyloric canal, and demonstrated a cleft between the hypertrophied muscle and the fibres of the pylorus itself. This appears to have been based, however, on a single specimen of adult hypertrophy, and it is doubtful if the cleft in the specimen could have been responsible for the niche, which varied in position, size, and shape, shown in the reproductions of the radiographs in his paper. The cleft was thought to produce a typical diamond-shaped central defect and has since been regarded as of diagnostic importance (McNaught, 1957; Shanks and Kerley, 1958; Sherman, Yen, Bowden, and

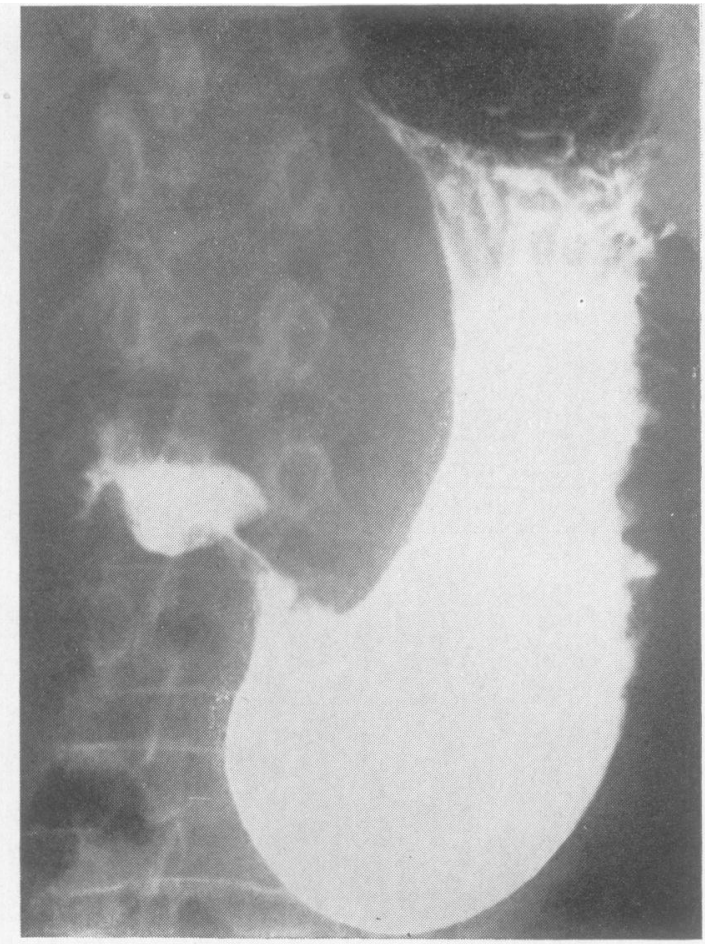

FIG. 6a.

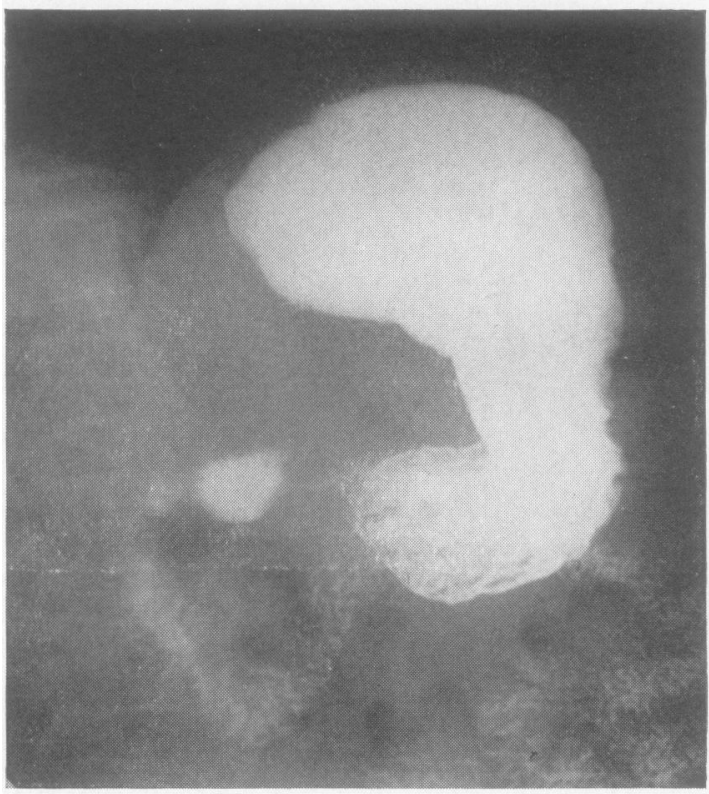

FIG. 6b.

FIGS. 6a and 6b. Adult pyloric hypertrophy(patient M.D.). Both views show elongation of the pyloric canal with some bulging of the pyloric muscle into the duodenal cap. There is some variation in the narrowing of the canal in the two radiographs. 


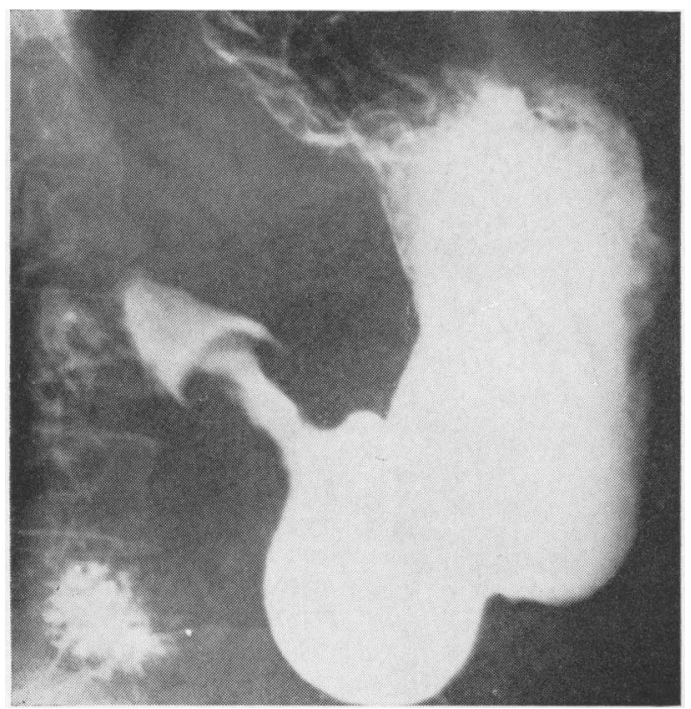

FIG. 7. Adult pyloric hypertrophy (patient C.S.). In this radiograph there is narrowing and elongation of the pyloric canal which shows a normal mucosal pattern. There is no bulging of the hypertrophied pyloric muscle into the base of the duodenal cap.

FIG. 8. Adult pyloric hypertrophy (patient C.S.). These radiographs show some variation in the narrowing of the elongated pyloric canal. The canal shows a funnel-shaped proximal end and there is no bulging of the pyloric muscle into the duodenal cap. 


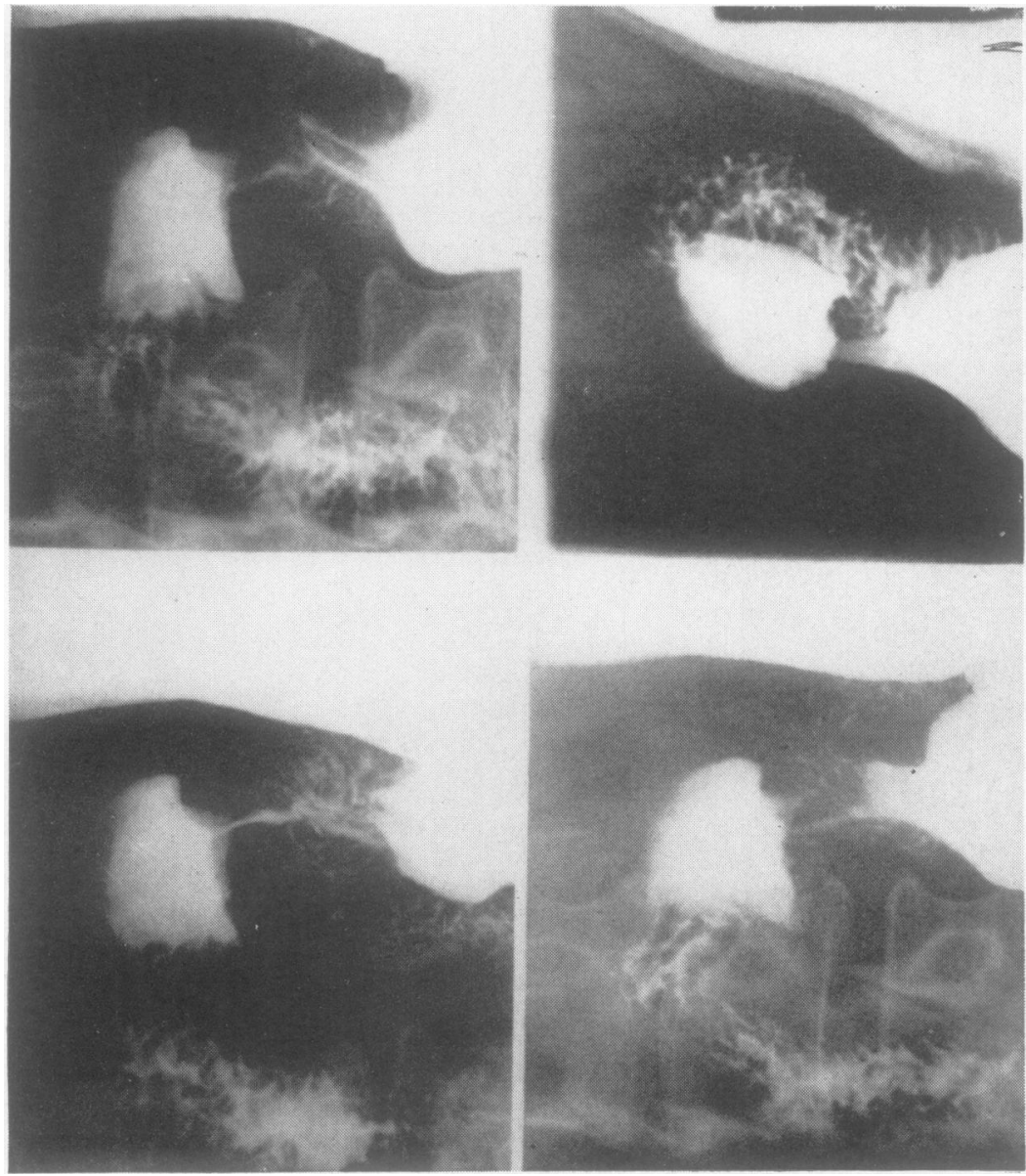

FIG. 9. Adult pyloric hypertrophy (patient A.K.). These radiographs show persistent narrowing of the pyloric canal and of the pre-pyloric region. There is no bulging of the hypertrophied muscle into the base of the duodenal cap. Ridges of gastric mucosa are visible in the pre-pyloric region.

Selby, 1959). This appearance was not seen in any of our cases.

Another radiological sign to which great significance has been attached is bulging of the hypertrophied muscle into the duodenal cap (Kirklin and Harris, 1933; Sherman et al., 1959). As early as 1933, however, Twining pointed out that this was not constant, even in cases showing this change. The indentation of the duodenal cap may only be present when the patient is prone, disappearing when he is erect, and it is now appreciated that pressure on the pyloric end of the stomach may push the pyloric muscle into the cap and produce the deformity in normal people. We therefore disregarded this appearance, unless it was consistently demonstrable when the patient was erect and no pressure was applied to the abdomen. It was present in one only of our patients with simple hypertrophy and in two of those with complicated hypertrophy.

Some accounts of the radiology of simple pyloric hypertrophy emphasize that the mucosal pattern is normal through the narrowed segment (Twining, 1933; McNaught, 1957; Shanks and Kerley, 1958). We confirmed this. We do not attach much significance to it because it it now realized that the mucosal pattern may remain normal when other layers of the stomach are infiltrated by tumour (Andersen, Gammelgaard, and de Fine Licht, 1946; Edwards, 1961).

Antispasmodics do not appear to alter the deformity due to the hypertrophied muscle, but this is of no help in distinguishing it from simple peptic ulceration or carcinoma. In one patient we gave first amyl nitrite and then a local anaesthetic (lignocaine) by mouth without effect on the radiological appearance. We do not know the effect of propantheline (probanthine) on the hypertrophied muscle.

We are able to review the radiographs of four of our patients in each group, and the results are summarized in Table I. On only one patient was pyloric hypertrophy suggested on radiology as a 
TABLE I

\begin{tabular}{|c|c|c|c|c|c|c|c|c|c|}
\hline & & & & LOGIC & DETAILS & OF EIGHT & CASES B & DRE OPE & ION \\
\hline Patient & Sex & Age & $\begin{array}{l}\text { Constant } \\
\text { Elongation of } \\
\text { Pyloric Canal }\end{array}$ & $\begin{array}{l}\text { Changes in } \\
\text { Shape of } \\
\text { Pyloric } \\
\text { Canal }\end{array}$ & Funnelling & $\begin{array}{l}\text { Indentation } \\
\text { of Duodenal } \\
\text { Cap }\end{array}$ & $\begin{array}{l}\text { Excess } \\
\text { Resting } \\
\text { Juice }\end{array}$ & $\begin{array}{l}\text { Evidence of } \\
\text { Peptic Ulcer } \\
\text { and Site }\end{array}$ & Radiological Diagnosis \\
\hline
\end{tabular}

\begin{tabular}{|c|c|c|c|c|c|c|c|c|c|}
\hline E.H. & $\mathbf{M}$ & 66 & + & + & + & $\mathbf{0}$ & + & $\mathbf{0}$ & Deformity pylorus, probable carcinoma \\
\hline M.D. & $\mathbf{F}$ & 57 & + & + & + & + & + & 0 & Pyloric stenosis ? carcinoma \\
\hline C.S. & $\mathbf{M}$ & 61 & + & + & + & $\mathbf{0}$ & + & $\mathbf{0}$ & Pyloric carcinoma \\
\hline A.By. & $\mathbf{F}$ & 67 & + & + & 0 & $\mathbf{0}$ & ++ & $\mathbf{0}$ & $\begin{array}{l}\text { Pyloric stenosis, probable muscle } \\
\text { hypertrophy }\end{array}$ \\
\hline A.Bu. & $\mathbf{F}$ & 60 & + & + & $\mathbf{0}$ & + & + & + D.U. & Pyloric stenosis with duodenal ulcer \\
\hline B.B. & $\mathbf{M}$ & 71 & + & 0 & $\mathbf{0}$ & $\mathbf{0}$ & 0 & 0 & $\begin{array}{l}\text { ? Pyloric carcinoma (subsequently } \\
\text { duodenal ulcer shown) }\end{array}$ \\
\hline A.K. & $\mathbf{F}$ & 50 & + & + & $\mathbf{0}$ & $\mathbf{0}$ & + & $+\mathbf{G . U}$ & $\begin{array}{l}\text { Pyloric stenosis ? carcinoma, gastric } \\
\text { ulcer }\end{array}$ \\
\hline K.H. & $\mathbf{M}$ & 60 & + & $\mathbf{0}$ & + & + & $\mathbf{0}$ & + P.U. & Pyloric stenosis with pyloric ulcer \\
\hline
\end{tabular}

probable diagnosis before operation. One common feature was present besides pyloric narrowing, and this was elongation of the pyloric canal. In the four patients with simple hypertrophy the shape of the canal varied, and this was also seen in two of the four patients with complicated hypertrophy. In the remaining two there was no variation, due presumably to fibrosis or oedema associated with the ulcer; carcinomatous infiltration may produce a similar narrowing and rigidity of the pyloric canal, so that the two conditions may be impossible to distinguish radiologically, unless there is a palpable mass typical of carcinoma.

The shape of the narrowed canal may be helpful, most carcinomas producing a shoulder-like deformity, whereas in pyloric muscle hypertrophy the proximal edge of the narrowed area is smooth and rounded, and the general shape is that of a funnel. 'Funnelling' was present in three of the cases of simple hypertrophy but in one only of the others (Table I). There was an excess of gastric resting juice seen in all patients with simple hypertrophy, and in two of those with complicated hypertrophy. This sign is so commonly present in conditions such as peptic ulcer and simple pyloric stenosis that it is unlikely to be of diagnostic value. Other radiological findings reported have included delayed emptying of the stomach (which may vary on repeat examinations), gastric dilatation, and vigorous peristalsis. These signs were all seen in some of our patients, but are not specific for pyloric hypertrophy. North and Johnson (1950) noted that in simple hypertrophy it is characteristic for 25 to $50 \%$ of the barium still to be present in the stomach after six hours and that it is rare to find complete gastric retention.

In summary, the only significant radiological sign of simple hypertrophic pyloric stenosis is elongation of a narrowed pyloric canal. The canal may vary in shape from time to time and often presents a funnel-shaped proximal end. We do not consider that these are sufficient criteria to exclude infiltrative carcinoma. The differential diagnosis may also include encircling myoma, mucosal prolapse, hypertrophic gastritis, or a pyloric ulcer with scarring. When the pyloric hypertrophy is focal, the contour of the pyloric canal may be irregular and there is less narrowing than when the disease is diffuse (Knight, 1961).

If the type of narrowing of the pyloric region described above is found at barium examination, we consider that the examination should berepeated with not more than two weeks' delay. If the same changes are still present, we believe that every patient should have a laparotomy. It may be possible for the radiologist to make a tentative diagnosis of hypertrophic pyloric stenosis but he can never completely exclude the presence of carcinoma. Archer (1930) Craver (1957), Knight (1961), and Sherman et al. (1959) also came to this conclusion, although the latter illustrate a case which is said to show specific changes and to indicate criteria on which a radiological diagnosis may be 'dependably' made. We do not agree with Kleitsch (1952) who states that the radiological changes are 'absolutely characteristic' and that they are 'readily recognizable'. Although in our series carcinoma was the most frequent preoperative diagnosis, Christiansen and Grantham (1962) found in their review of 58 patients with simple hypertrophy that peptic ulcer had been more commonly suspected by the radiologists than carcinoma; the correct diagnosis was most uncommon.

\section{CLINICAL FEATURES}

The clinical picture of simple adult pyloric hypertrophy is that of non-specific pyloric obstruction and diagnosis before operation has only occasionally been made (Craver, 1957). The symptoms may date from infancy, start in adult life and continue intermittently for a long time (often with increasing 
severity), or first occur in middle or late life with a comparatively short duration. In $70 \%$ of one series the age of onset was between 31 and 60 years (North and Johnson, 1950), and in another the average duration of symptoms was 12 years (Christiansen and Grantham, 1962). One of our six patients with simple hypertrophy had symptoms from childhood, three for over 30 years, and two for under 10 years. The patients with complicated hypertrophy, with one exception, had symptoms for 10 years or less (Table II). The variations in symptoms may be explained by the variable degree of stenosis produced by the hypertrophied muscle.

In most patients with simple hypertrophy, epigastric discomfort, or pain, made worse by food and relieved by vomiting, is the main symptom. A few have pain without vomiting, and in some vomiting without accompanying discomfort is the predominant symptom. Other complaints include anorexia, nausea, eructation, weight loss, and constipation. The pain does not usually occur at night, and is intermittent, of variable intensity, and not relieved by antacids. It is described as an epigastric fullness and does not radiate to the back. Gastric bleeding has only rarely occurred (Bastianelli 1925; Crymble and Walmsley, 1933; Christiansen and Grantham, 1962). In some, pyloric stenosis is an obvious diagnosis, and in patients with complicated hypertrophy the symptoms are usually those of peptic ulcer.

The physical findings are often negative, unless there is near-complete pyloric stenosis with succussion splash. Epigastric tenderness may be present. In two of our patients an epigastric swelling could be felt with varying ease, and in one of these the tumour could be felt to relax in between waves of visible gastric peristalsis. Such palpable pyloric tumours have only rarely been recorded.

Few reports have mentioned the results of gastric secretion studies. McCann and Dean (1950) found a high acid curve in one patient and achlorhydria in another, and Craver (1957) reported no free acid

TABLE II

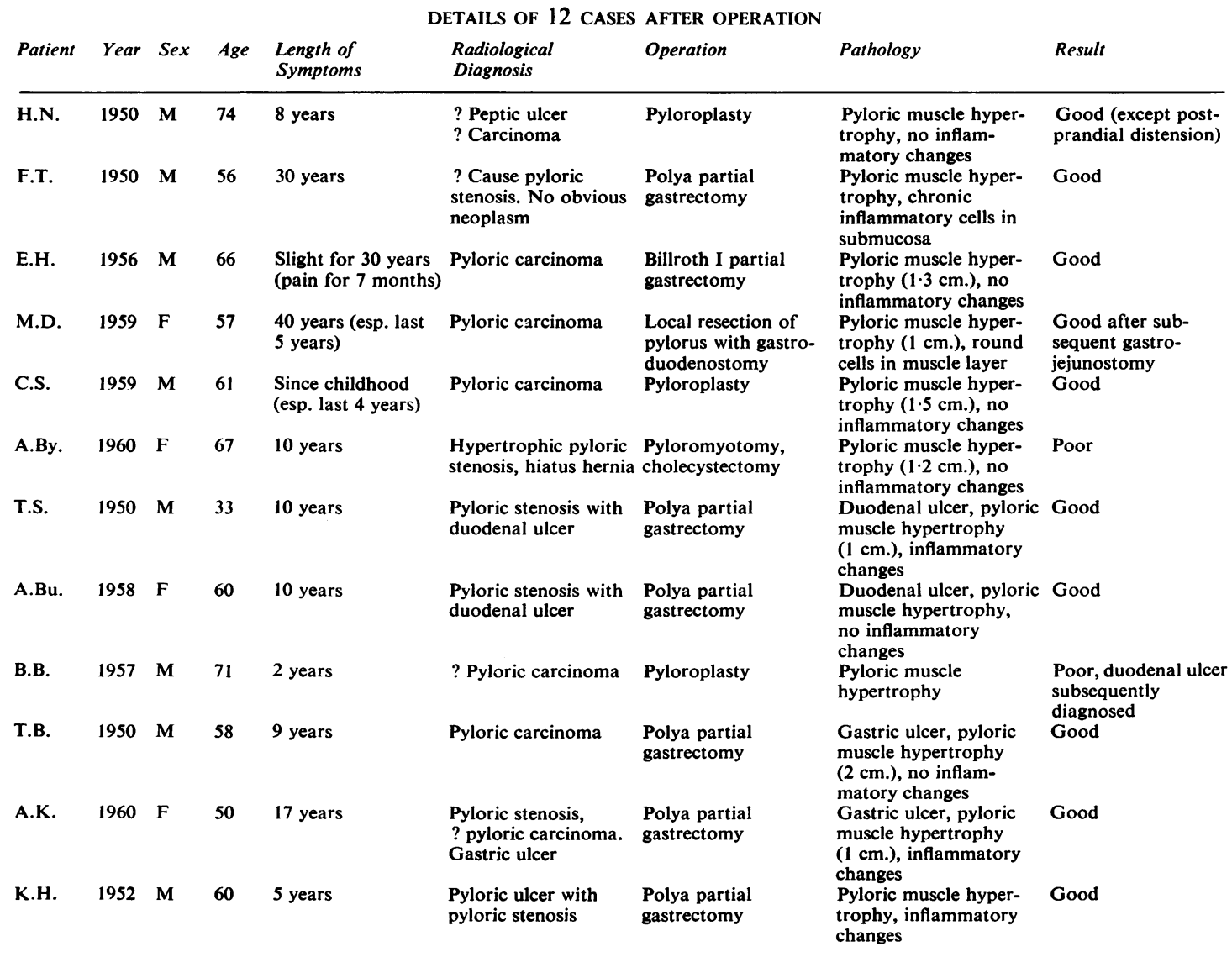


in the fasting juice, but a rise on giving histamine, in five of 11 patients with simple hypertrophy. One of our patients showed a high acid curve.

Gastroscopy in two of our patients showed a normal, mobile antrum; this investigation has rarely been reported (Lumsden and Truelove, 1958), and is of interest in view of the common pre-operative diagnosis of carcinoma. Search for malignant cells in gastric washings was negative in four patients on whom this was performed (Craver, 1957). These two investigations might prove useful in the future when the radiological findings suggest the possibility of pyloric hypertrophy. More usually, however, radiology will imply the need for early laparotomy, since a probable pyloric neoplasm is likely to be diagnosed, and without operation it will be difficult to exclude carcinoma, leiomyoma, or lymphoma.

Christiansen and Grantham (1962) noted in their review that 10 of 58 patients with simple pyloric hypertrophy had associated disease of the gall bladder or hiatus hernia. One of our patients on radiology showed a small hiatus hernia and at operation the gall bladder contained multiple stones.

\section{TREATMENT}

The treatment of hypertrophic pyloric stenosis in adults is surgical, because carcinoma cannot otherwise be excluded, and the patient requires relief of obstructive symptoms. A definite pre-operative diagnosis will be rare and even at operation the lesion may be difficult to recognize. The hypertrophy will cause a regular, concentric or eccentric, thickening of the pylorus covered by smooth serosa, and in the simple condition there will be no suggestion of peptic ulcer. In three of our patients, at least, the hypertrophied pyloric muscle could be felt to contract at operation, a fact which does not appear previously to have been emphasized.

If pyloric hypertrophy is not readily recognized, an opening may be made in the stomach near the proximal end of the swelling: the normal mucosa will be seen, and it is best not to divide the pyloric muscle until after the canal has been felt, because once the sphincter is cut assessment may be difficult. After this the incision may be extended into the tumour and part of the hypertrophied muscle sent for histology. If an ulcer is present, the operation to be performed will be that preferred for the ulcer. If wanted, the gastrotomy incision can be extended into the duodenum, and vagotomy and pyloroplasty (with biopsy) carried out.

Several operations have been used in the treatment of simple hypertrophic pyloric stenosis, but we favour a limited distal partial gastrectomy with gastro-duodenostomy. Recent authors have come to the same conclusion (North and Johnson, 1950;
Craver, 1957; Skoryna et al., 1959; Knight, 1961; Christiansen and Grantham, 1962). Simple dilatation has not been a success (Robson and Moynihan, 1901; Morton, 1930). A Ramstedt pyloromyotomy has not often been used and has disadvantages, which include, as McCann and Dean (1950) pointed out, possible diverticulum formation, pyloric scarring with only partial relief of the obstruction, and the leaving of an abnormal condition of the pylorus which might be a neoplasm. In the one patient in our series who had this operation the obstruction was only partially relieved, though no further operation was necessary.

Gastro-enterostomy has had a limited use and was recommended by Craver (1957) in debilitated patients. It has, however, been followed in some by recurrence of symptoms, or a failure to relieve the symptoms (McCann and Dean, 1950), and in addition there are the disadvantages that histological confirmation is not obtained and a stomal ulcer might develop.

Pyloroplasty by the method of Finney or of Heinecke and Mikulicz has recently been recommended by Feraru et al. (1961) and can give good results, though Christiansen and Grantham (1962) found that there had been a poor result in three of 16 patients with simple hypertrophy treated by this method. Feraru et al. (1961) point out that the opening in the stomach made for confirmation of the diagnosis can easily be extended into the duodenum for this procedure. They favoured the Finney manoeuvre because of the difficulty of transverse closure in the presence of the large muscle mass. Besides the difficulty of closure, pyloroplasty may have the disadvantages of obtaining insufficient tissue for adequate histology and the overlooking of an associated peptic ulcer. In our series three patients underwent pyloroplasty, with a satisfactory result in two and a poor result in one who was subsequently shown to have a duodenal ulcer.

One of our patients with simple hypertrophy, who underwent local sleeve resection of the tumour with gastro-duodenostomy (Billroth I type operation), developed stenosis at the anastomosis, which was treated by gastro-jejunostomy. Another patient had a good result from a Billroth I procedure. From our small number of patients with simple hypertrophic pyloric stenosis it is not possible to decide whether a limited Billroth I partial gastrectomy is preferable to pyloroplasty, but we believe that it should be preferred, since it involves little additional risk and removes the whole lesion (with any associated, but perhaps unrecognized, local disease) for histology, and in the literature has given better results. A Polya-type partial gastrectomy will also give good results, but is almost certainly less desirable. 


\section{AETIOLOGY}

The aetiology of hypertrophic pyloric stenosis in the adult remains obscure, even in the complicated condition (usually called 'secondary') with associated peptic ulcer, polyposis, or hypertrophic gastritis. With proximal gastric ulceration it has been suggested that the ulceration is secondary to the pyloric stenosis (McCann and Dean, 1950; Dragstedt, Oberhelman, Evans, and Rigler, 1954; Johnson, 1955; Skoryna et al., 1959), and Christiansen and Grantham (1962) considered that the stenosis might also be the cause of the hypertrophic gastritis and polyposis. But this does not explain the pyloric hypertrophy any more than why a small proportion of patients with duodenal or pyloric canal ulcers are found to have it, nor why biliary tract disease or hiatus hernia has been found in about $17 \%$ of patients with simple pyloric hypertrophy (Christiansen and Grantham, 1962).

Many authors have suggested that simple adult pyloric hypertrophy is congenital in origin with persistence of infantile hypertrophy into adult life, though the late onset of symptoms in some patients has caused others to doubt this theory. The persistent hypertrophy may fail to give, or may cause intermittent, symptoms until a complicating factor, such as inflammation, oedema, spasm, or 'autonomic dysfunction', precipitates pyloric occlusion. Most previous writers appear to have assumed that the associated lesion (particularly a duodenal or pyloric canal ulcer) is the cause of the hypertrophied muscle in what they have called 'secondary hypertrophy' rather than that the associated lesion develops in patients who already have pyloric hypertrophy.

There is no exact analogy elsewhere in the adult body for the development of a similar lesion to pyloric muscle hypertrophy which, for instance, appears to be different from muscular hypertrophy of the lower oesophagus (Sloper, 1954). No good explanation has even been given how an associated lesion might produce it, nor how the condition might arise de novo in the adult. One theory has been that of spasm, but it is unlikely that severe and protracted spasm could lead to hypertrophy or thickening of a smooth muscle sphincter such as the pylorus; it is not seen elsewhere in the body, and spasm of the pylorus is often reported by radiologists without the finding of pyloric hypertrophy. Skoryna et al. (1959) thought that peptic ulceration at or near the pyloric canal could explain hypertrophy of the pyloric muscle, both simple and complicated, though by definition specimens of the simple hypertrophy show no evidence of ulceration. The paper by Boerema (1948) has suggested that a dietary deficiency might be a causative factor in simple adult pyloric hypertrophy; it might be a precipitating cause for symptoms in some cases, perhaps.

In some patients with simple pyloric hypertrophy the symptoms continue throughout infancy and childhood into adult life. North and Johnson (1950) found this in a quarter of the patients in their review, although Christiansen and Grantham (1962) noted it in only three of their 58 patients. But a more common history is the more-or-less abrupt start of dyspepsia in middle age, and this has been used as an argument against the persistence of congenital hypertrophy in, some at least, of these adult patients.

It has been clearly shown that congenital pyloric hypertrophy can persist into adult life, unless treated by pyloromyotomy (Rammstedt, 1912; Holt, 1917; Armitage and Rhind, 1951; Lumsden and Truelove, 1958). Runström (1939) studied 107 children with congenital pyloric stenosis treated medically and showed that the radiological abnormalities became less frequent with advancing years, but were still present long after there were no symptoms. Lumsden and Truelove (1958), in 17 patients between the ages of 14 and 25 years, confirmed this and showed that the fading-out process continued into full adult life. They also noted that it is uncommon for symptoms of pyloric stenosis to persist into adult life. Nielsen and Roelsgaard (1956) examined 45 adult patients (37 men and eight women aged from between 25 and 50 years) who had been treated medically for pyloric stenosis in infancy and found radiological evidence of residual stenosis in 35 , as well as evidence of peptic ulcer in 14 (eight duodenal, five pyloric, and one gastric). Nineteen of their 45 patients $(42 \%)$ had dyspepsia symptoms, and these did not include all those with ulcers. A complicating peptic ulcer appears to be common when there are known persistent signs of congenital hypertrophy in the adult.

We conclude that persistence, or delayed development, of 'congenital pyloric hypertrophy' is the cause of adult hypertrophy, both simple and complicated, but admit that this theory is difficult to prove. It is hard to explain the long gap between birth and the onset of symptoms in some patients or why the hypertrophy might worsen later in life. A complicating factor, such as mucosal oedema (Runström, 1939), may precipitate the symptoms of pyloric occlusion. It is probably relevant to note, therefore, that complicated adult hypertrophy is more common than the simple variety, and that usually the duration of symptoms is shorter.

Carter and Powell (1954) have shown a familial tendency in the infantile hypertrophy, and there are now two records suggesting that the adult and infantile diseases, are in fact, the same condition only 
differing in the age of presentation. Fenwick (1953) reported a man with the adult form of the disease, two of whose four sons had the infantile form, and Woo-Ming (1961) another man with two sons and one daughter, whose second son had congenital pyloric stenosis. ${ }^{1}$ A difficulty remains, however, in explaining why the male sex predominance of two males to one female in the adult simple condition is lower than that in the infantile disease (four to one), but the difference may disappear if patients with complicated hypertrophy are added to those with the simple disease.

The cause of the infantile form, is at least, part genetic (Carter, 1961). As measured by clinical manifestation, however, it cannot be wholly genetic, because then all monozygote co-twins would be affected and in fact less than half are so affected. It could still be that the presence of the hypertrophy is entirely genetically determined and that environmental or other factors decide whether the hypertrophy leads to stenosis (Carter, 1961 and 1963). A genetic factor in the causation of infantile pyloric hypertrophy gives further credence to the idea that both adult forms are due to its persistence or late development.

The histology of the infantile and the simple and complicated adult types of pyloric hypertrophy is similar; it is not known whether there is hyperplasia of the muscle fibres as well as hypertrophy. Cameron (1925) suggested that neuromuscular incoordination due to changes in Auerbach's plexus might account for the infantile hypertrophy. Various workers have described changes in the ganglion cells, but with little agreement as to what the changes are (Belding and Kernohan, 1953; Raia et al., 1956; Friesen, Boley, and Miller, 1956; Lane-Roberts, 1959). In our adult material there was no apparent abnormality in the number and appearances of the ganglion cells, and workers at the Hospital for Sick Children, Great Ormond Street, likewise believe that the ganglion cells are normal in infantile hypertrophy and that any changes have been secondary (Bodian, 1963). A genetic cause need entail no abnormality in the ganglion cells and could imply perhaps that the formation de novo of an identical lesion in the adult is unlikely. These considerations suggest, indeed, that both forms of adult pyloric muscle hypertrophy are due to 'congenital hypertrophy'. No good explanation has ever been given how the lesion might otherwise be present or acquired in adult life.

${ }^{1}$ If the infantile and adult conditions are essentially the same one might find as high an incidence of infantile pyloric stenosis in the children of the adult patients as in the children of those who themselves had infantile pyloric stenosis. One would need about 200 offspring to demonstrate this, but would get some indication with about 100 (Carter, 1963).

\section{SUMMARY}

Hypertrophy of the pyloric muscle similar to that seen in congenital pyloric stenosis is described in 12 adults. In six of these the hypertrophy was simple, and in six it was complicated by a peptic ulcer. The clinical, radiological, and pathological features are discussed with the surgical treatment of this condition.

The symptoms of simple pyloric hypertrophy are those of non-specific pyloric stenosis, and radiological examination is unlikely to distinguish it with certainty from carcinoma of the pylorus. Reasons are given for preferring as treatment a limited distal partial gastrectomy with gastro-duodenostomy, rather than pyloroplasty, though either may give good results.

It is suggested that both simple and complicated pyloric hypertrophy are due to the persistence, or late development, of 'congenital pyloric hypertrophy', and that the cause is genetic. An associated peptic ulcer appears not to be the cause of the hypertrophy but may develop in patients who already have hypertrophy. Complicated hypertrophy is more common than simple hypertrophy.

I am indebted to the staff of St. Bartholomew's Hospital for permission to report on their patients, and to Mr. C. Naunton Morgan for the record from the Royal Masonic Hospital. I wish to thank Mr. C. Naughton Morgan, Mr. D. F. Ellison Nash, Dr. R. A. Kemp Harper, Dr. C. O Carter, and Dr. R. J. R. Cureton for their help and encouragement, and particularly Dr. David Trapnell for his help with the radiological aspects of this paper.

\section{REFERENCES}

Andersen, K., Gammelgaard, A., and de Fine Licht, E. (1946). Hypertrophy of the pylorus in adults. Acta radiol. (Stockh.), 27, 552-568.

Archer, V. W. (1930). Hypertrophic pyloric stenosis in adults: roentgen aspects. Amer. J. Roentgenol., 23, 510-515.

Armitage, G., and Rhind, J. A. (1951). The fate of the tumour in infantile hypertrophic pyloric stenosis. Brit. J. Surg., 39, 39-43.

Bachmann, K. D. (1952). Úber umschriebene, plattenförmige Muskelhyperplasien in Antrum und Pylorous ('Muskelplatten'). Beitr. path. Anat., 112, 97-103.

Barling, H. G. (1913). Hypertrophic stenosis of the pylorus in adults Lancet, 1, 231-232.

Bastianelli, R. (1925). Pyloric spasm and its surgical treatment. Ann. Surg., 81, 45-51.

Belding, H. H., III., and Kernohan, J. W. (1953). A morphologic study of the myenteric plexus and musculature of the pylorus with special reference to the changes in hypertrophic pyloric stenosis. Surg. Gynec. Obstet., 97, 322-334.

Bodian, M. (1963). Personal communication.

Boerema, I. (1948). Gastroduodenal ulcer, a spastic disease. Ann. Surg., 127, 413-416.

Cameron, H. C. (1925). Some forms of vomiting in infancy. II. Vomiting due to obstruction from neuromuscular incoordination. Brit. med. J., 1, 815-820.

Carter, C. O. (1961). The inheritance of congenital pyloric stenosis. Brit. med. Bull., 17, 251-254.

(1963). Personal communication.

and Powell, B. W. (1954). Two-generation pyloric stenosis Lancet, 1, 746-748. 
Christiansen, K. H., and Grantham, A. (1962). Idiopathic hypertrophic pyloric stenosis in the adult. Arch. Surg., 85, 207-214.

Craver, W. L. (1957). Hypertrophic pyloric stenosis in adults. Gastroenterology, 33, 914-924.

Crymble, P. T., and Walmsley, T. (1933). Hypertrophy of the pylorus in an adult. Brit. J. Surg., 20, 602-606.

Cruveilhier, J. (1835), Rétrécissement du pylore. In Anatomie Pathologique du Corps Humain, vol. 1., no. 12, pt. 4. J. B. Baillière, Paris.

Cunningham, D. J. (1906). The varying form of the stomach in man and the anthropoid ape. Trans. roy. Soc. Edinb., 45, 9-47

Desmond, A. M., and Swynnerton, B. F. (1957). Adult hypertrophy of the pylorus. Brit. med. J., 1, 968-971.

Dragstedt, L. R., Oberhelman, H. A., Jr., Evans, S. O., and Rigler, S. P. (1954). Antrum hyperfunction and gastric ulcer. Ann. Surg., 140, 396-404.

Edwards, D. (1961). Some radiological aspects of pyloric disease. Proc. roy. Soc. Med., 54, 933-937.

Fenwick, T. (1953). Familial hypertrophic pyloric stenosis. Brit. med. J., 2, 12-14.

Feraru, F., Rosemond, G. P., Irons, H. S., Jr., and Zaino, L. J. (1961). Hypertrophic pyloric stenosis in adult patients. Ann. Surg., 154, 847-850.

Friesen, S. R., Boley, J. O., and Miller, D. R. (1956). The myenteric plexus of the pylorus; its early normal development and its changes in hypertrophic pyloric stenosis. Surgery, 39, 21-29.

Graham, H. F. (1920). The Rammstedt operation in adults. Surg. Gynec. Obstet., 30, 208-209.

Holt, L. E. (1917). Hypertrophic stenosis in infants. J. Amer. med. Assn., 68, 1517-1524.

Horton, B. T. (1928). Pyloric musculature, with special reference to pyloric block. Amer. J. Anat., 41, 197-225.

Horwitz, A., Alvarez, W. C., and Ascanio, H. (1929). The normal thickness of the pyloric muscle and the influence on it of ulcer, gastroenterostomy, and carcinoma. Ann. Surg., 89, 521-528.

Johnson, H. D. (1955). The special significance of concomitant gastric and duodenal ulcers. Lancet, 1, 266-270.

Keet, A. D. Jr. (1956). Focal hypertrophy of the pyloric musculature in adults. Arch. Path., 61, 20-23.

Kirklin, B. R., and Harris, M. T. (1933). Hypertrophy of the pyloric muscle of adults: a distinctive roentgenologic sign. Amer. $J$. Roentgenol., 29, 437-442.

Kleitsch, W. P. (1952). Diagnosis and treatment of pyloric hypertrophy in the adult. Arch. Surg., 65, 655-664.

Knight, C. D. (1961). Hypertrophic pyloric stenosis in the adult. Ann. Surg., 153, 899-910.

Lane-Roberts, P. A. (1959). Pathology of infantile hypertrophic pyloric stenosis. Proc. roy. Soc. Med., 52, 1022-1023.

Lumsden, K., and Truelove, S. C. (1958). Primary hypertrophic pyloric stenosis in the adult. Brit. J. Radiol., 31, 261-266.

Maier, R. (1885). Beiträge zur angeborenen. Pylorusstenose. Virchows. Arch. path. Anat., 102, 413-434.
McCann, J. C., and Dean, M. A. (1950). Hypertrophy of pyloric muscle in adult. Surg. Gynec. Obstet., 90, 535-542.

McLaughlin, R. T., and Madding, G. F. (1962). Primary pyloric hypertrophy in the adult. Amer. J. Surg., 104, 874-878.

McNamee, E. P. (1933). Pyloric stenosis with hypertrophy of the pyloric muscle in the adult. Amer. J. Roentgenol., 29, 24-30.

McNaught, G. H. D. (1957). Simple pyloric hypertrophy in the adult. J. roy. Coll. Surg. Edinb., 3, 35-41.

Morton, C. B. (1930). Hypertonicity with hypertrophy of the pylorus in adults. Arch. Surg., 20, 508-514.

Nielsen, O. S., and Roelsgaard, M. (1956). Roentgenologically demonstrable gastric abnormalities in cases of previous congenital pyloric stenosis. Acta radiol. (Stockh.), 45, 273-282.

North, J. P., and Johnson, J. H. Jr. (1950). Pyloric hypertrophy in the adult. Ann. Surg., 131, 316-329.

Prinz, H. (1939). Zur Frage der Pylorushypertrophie des Erwachsenen unter besonderer Berücksichtigung bestimmter Formen des Pförtnerkrebses. Langenbecks Arch. klin. Chir., 197, 1-114.

Raia, A., Curti, P., Cardoso de Almeida, A., and Fry, W. (1956). The pathogenesis of hypertrophic stenosis of the pylorus in the newborn and the adult. Surg. Gynec. Obstet., 102, 705-712.

Rammstedt, W. C. (1912). Zur operation de angeborenen Pylorusstenose. Med. Klin., 8, 1072-1705.

Robson, A. W. M., and Moynihan, B. G. A. (1901). Diseases of the stomach and their surgical treatment, pp. 42-43. Baillière, London.

Runström, G. (1939). On the roentgen-anatomical appearance of congenital pyloric stenosis during and after the manifest stage of the disease. Acta paediat. (Uppsala), 26, 383-433.

Shanks, S. C., and Kerley, P., eds. (1958). A Textbook of X-ray Diagnosis by British authors, 3rd ed., vol. 3, pp. 170-172. H. K. Lewis, London.

Sherman, R. S., Yen, Y.-M., Bowden, L., and Selby, H. M. (1959). Ther oentgen diagnosis and management of prepyloric narrowings. Amer. J. Roentgenol., 81, 582-598.

Skoryna, S. C., Dolan, H. S., and Gley, A. (1959). Development of primary pyloric hypertrophy in adults in relation to the structure and function of the pyloric canal. Surg. Gynec. Obstet., 108, 83-92.

Sloper, J. C. (1954). Idiopathic diffuse muscular hypertrophy of the lower oesophagus. Thorax, 9, 136-146.

Torgersen, J. (1942). The muscular build and movements of the stomach and duodenal bulb. Acta radiol. (Stockh.), suppl. 45.

Twining, E. W. (1933). Chronic hypertrophic stenosis of the pylorus in adults. Brit. J. Radiol., 6, 644-655.

Wollstein, M. (1922). Healing of hypertrophic pyloric stenosis after Fredet-Rammstedt operation. Amer. J. Dis. Child., 23, 511-517.

Woo-Ming, M. (1961). Familial relationship between adult and infantile hypertrophic pyloric stenosis. Brit. med. J., 1, 476.

Zacho, A. (1948). Relaxation of the gastric mucosa producing pyloric obstruction. Arch. Surg., 57, 45-50. 